\section{THE RELATION OF THE PANCREAS TO DIABETES AND THE QUESTION OF THE TRANSPLANTATION OF THAT GLAND AS A REMEDY FOR THE DISEASE.}

BY JAMES W. ALLAN, M.B., O.M. GLASG., PHYSICLAN TO THE GLASGOW ROYAL INFIRMARY.

THE grave form of diabetes is not only hopeless but the patient is always liable to the sudden development of comaand death. Therefore, it is not only justifiable but right that any method of treatment which holds out a reasonable hope of success should be tried if, after full explanation, the patient is willing to submit to it.

There is a great mass of eridence, physiological and pathological, pointing to disease of the pancreas (in some cases it may be only functional disorder of the pancreas) as one of the factors, probably the chief factor, in the production of diabetes. The physiology of the pancreas and its relation to diabetes have been carefully and laboriously investigated by a host of skilful and scientific observers, among whom may be mentioned Minkowsky, von Mering, De Dominis, Thiroloix, Hédon, and Lepine. It seems sad if out of all this mass of painstaking experiment and investigation we cannot obtain some therapentic help for thoie cases of diabetes not amenable to dieting or to drug treatment and always more or less in danger of diabetic coma. In this connexion the following points may be considered. 1 . It is well known that total extirpation of the pancreas induces diabetes. 2. If only a portion of the pancreas is left-even the splenic end-no diabetes occurs. 3. If pancreas is transplanted into an animal before its own pancreas is cut out no diabetes takes place. If the graft is removed diabetes occurs (Minkowsky, referred to by Williamson in Gibson's Medicine). 4. From 2 and 3 it is evident that the prevention of glycosuria is not due to the ordinary secretion of the pancreas, which flows into the duodenum by the duct of Wirsung. 5. It is reasonable to assume that the organ produces an internal sugar-destroying secretion (as contended by Lepine) and that the portion of gland left (2) or the transplanted gland (3) has the powe of forming that sugar-destroying secretion or juice. 6 . From the foregoing it might therefore be hoped that by transplantation of pancreas a case of diabetes might be cured or relieved. 7. Again, turning to the patho logical aspect of the question, we find that disease of the pancreas is frequently associated with diabetes, as is shown post mortem. This is well known and it is perhaps, unnecessary to cite particular instances. 8. But it must be admitted that there are many cases of diabetes in which no disease of the pancreas is detected. How are we to explain these cases? In the first place, a naked-eye examination may fail to reveal changes in the organ and it may be hastily pronounced "normal" or " healthy." But the real question is, Has the gland been subjected to a carefnl microscopic examination by a skilled observer and does that examination show the islands of Langerhans to be in a healthy condition? for in those islands the sugardestroying ferment, the "internal secretion" of Lepine, is produced.

Supposing, however, that in a case of diabetes the pancreas presents healthy normal appearances, both macroscopically and microscopically, are we to conclude that the disease cannot be due to the pancreas in any way? The reply is that there may be a defect in the innervation of the organ, its secretions may be checked by inbibitory nervous action-due to irritation or disease in the nerve centres, say in the floor of the fourth ventricle. I do not possess the profound or intimate knowledge of physiology to enable me to discuss this matter fully and if I did space would forbid. I shall therefore content moself with saying that it is well known that irritation at a certain spot on the floor of the fourth ventricle gives rise to glycosuria. (Osler mentions a curious case which he saw with Reis in Berlin where a woman who had "anomalous cerebral symptoms and diabetes" was found on post-mortem examination to have a cysticercus in the fourth ventricle. ${ }^{1}$ )
It is recognised that many cases of diabetes mellitus date, it may be immediately, from a mental shock or strong emotion. Is not this analogous to the jaundice which has been known to supervene on strong emotion of disgust. (A case in point has come under my observation.) In this instance it is to be presumed that the nervous influence disorders the function of the liver. In the case of diabetes due to shock may it not be a similar influence affecting the pancreas?

One other point. It may be urged that there are cases of disease of the pancreas with no diabetes. The question here is, Are the islands of Langerhans destroyed or not? If not the sugar-destroying function of the organ may remain.

It seems pretty clear, then, that the revelations of disease support the idea that there is a close association between the pancreas and diabetes. Pathologists tell us that hyperplasia of the intestinal mucous membrane is the most constant post-mortem appearance in diabetes. Granting this to be the case this hypertrophy is very probably secondary to pancreatic mischief, as it has been found to follow in cases of glycosuria indaced by extirpation of the pancreas. This is important. Hédon says : "Chez les animaux qui ont survéca longtemps, on observe une ectasie parfois considérable de l'estomac et de l'intestin, avec hypertrophie de la tunique muqueuse (et développement anormal des glandes de Lieberkühn d'après Martinotti et Boccardi)." Other pathological changes, also presumably secondary, are mentioned by Hédon ${ }^{2}$ : "Le tissu du foie peut pré:enter cependant un état de dégénérescence graisseuse plus ou moins avancé ( $v$. Mering $t \mathrm{t}$ Minkowski) ...... les reins sont aussi notablement hypertrophiés, ainsi que la vessie. Dans la moelle, Boccardi a rencontré une dégénérescence de la myéline et l'atrophie de certaines cellules nerveuse." These remarks come under the heading: "Extirpation totale du pancreas." Surely the pathological changes in liver, intestine, kidneys, and cord are very significant.

In myxodema and cretinism benefit has been obtained by implanting thyroid gland. Only two instances need be cited here-Macpherson's ${ }^{3}$ and Gibson's. ${ }^{1}$ In the former the thyroid of a sheep was transplanted, a half under each mamma. The result was immediate improvement, due no doubt to "the absorption of secretion of the thyroid gland. But I have also reason to believe that a considerable portion of the gland I grafted became ultimately vascularised in the body of the patient." In the latter lamb's thyroid was employed in a child (myxcedematous sporadic cretin). The first grafting was under the sheath of the great pectoral just below the nipple, each lobe being laid open before insertion. In the second grafting one lobe was attached by a silkwormgut stitch to the anterior left abdominal wall, the other being placed free in the right side of the abdominal cavity. I abstain from further details of these very interesting cases in order to economise space. I have selected these cases because the thyroid of an animal was employed, not human thyroid. Marray, Byrom Bramwell, Kocher, and Fenwick have done work in this field which is known to all the world. Oomplete extirpation of the thyroid induces myxœdema or cretinism ; implantation of thyroid cures or relieves sufferers from myxœdema or cretinism. With these experiences before us, are we not justified in hoping that similar beneficial results may be got ${ }^{\circ}$ by the implantation of pancreas in diabetes? It is to be remembered that the production of the "internal secretion"--the sugar-destroying ferment-is now referred to the islands of Langerhans and these islands are in structure similar to the thyroid inasmuch as they are closed ductless glands.

To sum up, physiological experiments, pathological experience, and the results of implanting thyroid in myxoedema all point to transplantation of pancreas in diabetes as a reasonable and justifiable proceeding. It may be urged against the proposal that the diabetic patient is a bad subject for surgical interference. I fear it must be admitted that he is not a desirable subject for operation. At the same time we must not overlook the fact that the myzodematous patient is pretty much in the same category and that in his case transplantation of gland (although not unattended by some troublesome circumstances) has yielded happy results.

The labours of Murray and others have happily shown us that operation is not necessary for the relief of myxœedema.

2 Physiologie Normale et Pathologique du Pancréas, p. 151. \& Brit. Med. Jour., Jan. 14th, 1893. 
We know that the internal administration of the gland is attended with equally satisfactory results. But in the case of diabetes the internal administration of pancreas has given disappointment and therefore (in the meantime at least) we are compelled to turn our eyes to operative interference. Dr. P. Watson Williams of Clifton ${ }^{5}$ has recorded an attempt to transplant pancreas in diabetes and another attempt was recently made in Glasgow Royal Infirmary. ${ }^{6}$ Unfortunately, both of these were unsuccessful. Dr. Williams's case is very interesting and worthy of careful attention. One important fact in connexion with it I may note. The stools were not fatty, but on post-mortem examination the pancreas was found to be atrophied and wasted-a mass of connective tissue with little gland substance left.

This present communication does not aim at urging the operation. My object is to call the attention of my professional brethren to a very interesting and important question in practical therapeutics and to elicit the opinions of those who have more knowledge than myself.

It only remains to be said that if I had a case of diabetes under my care which refused to respond to dietetic or drug treatment and was drifting within range of diabetic coma I should be willing again to assume the responsibility of advising transplantation of pancreas on the following con. ditions : (1) that after full and honest explanation of pros and cons the patient requests that the operation shall be performed; (2) that the patient shall not be suffering from acetoruria at the time; and (3) that a sheep shall be killed close to, or in, the place of operation and its pancreas directly conveyed to the body of the patient.

Glasgow.

\section{A CASE OF DERMOID CYST OF THE MESENTERY.}

By J. BASIL HALL, M.C. CANTAB.,

HONORARY SURGEON TO THE ROYAL INFIRMARY, BRADFORD.

ALTHOUGH the existence of mesenteric cysts has been recognised for nearly four centuries it is only within the last 20 years that any systematic study of the subject has been made. In English surgical literature, however, very little except the records of isolated cases appeared until six years ago when Moynihan ${ }^{1}$ published a valuable con tribution in which he gave a comprehensive classification of the various forms of cyst that had been found in this situation. It was largely due to my knowledge of Moynihan's article and to my previous association with one of the cases which he recorded therein that I was able to recognise the condition prior to operation in the case which $I$ now record.

The patient, a girl, aged eight years, was sent to me by Dr. H. Munro of Bradford on March 20th, 1903. Her mother stated that she had first noticed a lump in the child's abdomen four months prior to my seeing her. About three we eks later the patient had diphtheria and went into the fever hospital. The attack was followed by some diphtheritic paralysis. Since returning home the abdominal tumour had increased very considerably in size but had given rise to no symptoms. The patient's condition on examination was as follows. She was a well-grown girl of rather fragile appearance and somewhat thin. There were a distinct nasal intonation and some slight paralysis of the palate still remaining. The knee-jerks were absent and the pulse was quick, varying from 100 to 120 per minute. In other respects the general health appeared to be good. On uncovering the abdomen a prominent tumour was seen on the right of the middle line at the level of the umbilicus. It felt to be of about the size of an English melon and was smooth and globular. In consistence it was highly elastic. It was dull on percussion and there was no tenderness. When the patient lay on her back it sank most readily into the right lumbar region. It could easily be displaced, however, to the left of the middle line and also downwards towards the pelvis, and when displaced it remained in its new position. It was quite free from any liver attachment and the colon did not lie in front of it. Its extreme mobility also negatived the possi. bility of renal origin. No connexion with the pelvic organs could be demonstrated and, moreover, of all its movements that in a downward direction was the most limited. The urine was normal as were also the intestinal functions. There was no history of any subjective symptoms obtainable. The diagnosis of mesenteric cyst was made, but in view of the post.diphtheritic palsy it was decided to wait for a short period before operating. The patient was kept in bed for three weeks under medical treatment during which time her general condition much improved. The tumour did not perceptibly increase in size during this period.

Operation.-On April 16th ether was administered and the abdomen was opened through the sheath of the right rectus muscle. A cystic tumour was found lying in the mesentery of the ileum. The cyst wall was thick and pearly-white in colour and very scantily supplied with blood vessels. At this stage the pulse became alarmingly rapid and it was evident that the patient would not endure any prolonged operation. The edges of the incision were therefore attached to the cyst with a few sutures and the wound was packed with gauze. For the next two days the child was very ill, with a very rapid pulse and symptoms of shock. She then improved and soon seemed none the worse. This alarming collapse could only be attributed to the postdiphtheritic state and it was decided simply to incise the cyst and to drain it as soon as adhesions had formed. On April 23rd, therefore, ether was again given and the dressings were removed. It was then found that no adhesions had formed between the cyst and the abdominal wall and as the patient bore the anæs. thetic well it was decided to attempt removal. The abdo. minal cavity was packed off with gauze and the cyst was incised. A pint of thick creamy fluid escaped. The cyst wall was easily peeled from the mesentery with the exception of a couple of square inches which were closely incorporated and could not be removed without endangering the blood-supply of the gut. The whole cyst wall, therefore, was cut away excepting this small area which was fixed to the edges of the peritoneum in the lower parts of the wound. This portion of the incision was left open and packed with gauze whilst the upper half was closed with sutures. The patient bore the operation well. The portion of the wound which was packed healed by granulation in eight weeks and left a firm scar. The child has continued in excellent health since the operation.

The disposition of the tumour and the viscera when the abdomen was opened was as follows. The cyst, which was as large as a cocoanut, lay in the mesentery of the ileum. It cccupied the whole breadth of it except for an inch on either side at the fixed and free borders. The narrow strip of mesentery between the gut and the cyst was abnormaily thick and fleshy. So far as it was possible to estimate by a rapid survey its site was about 25 inches above the ileocæcal valve. There was no ascending colon; the cæcum and appendix were lying in the epigastrium above and to the left of the tumour. The ileum therefore almost completely єncircled the cyst, passing first along its lower border, then up the right side, and finally above it from left to right to reach the cæcum in the epigastrium. In front of the cyst the anterior or upper layer of the mesentery had practically disappeared from atrophy so that only the posterior aspect of the tumour had any mesenteric attach. ment. The cyst contained a pint of thick creamy material of treacly consistence. There were a very few fine hairs in it and some pasty masses which appeared to be conglomera. tions of flattened epithelium. There were large quantities of oil globules which blackened when treated with osmic acid. The interior of the cyst wall was granular and roughened as if inflammatory changes had occurred in it. There were also considerable patches of ecchymosis in the wall. Sections under the microscope failed to demonstrate any epithelial lining, the latter having apparently been entirely destroyed. There seems no doubt, therefore, that the tumour was a dermoid cyst of the mesentery in which degenerative changes had occurred.

The case appears to me to possess an interest over and above those hitherto recorded from the fact that the conditions found at the operation seem to have some bearing on the etiology of the growth. The situation of the cyst was that in which the remains of the vitelline duct are not uncommonly found and the large intestine was imperfectly developed. The cæcum occupied the position which is attained about the third month of fotal life. Whilst the 